\title{
THE NORMAL AND ABNORMAL INTER-ATRIAL SEPTUM
}

\author{
BY \\ REGINALD HUDSON \\ From the Institute of Cardiology and National Heart Hospital \\ Received April 5, 1954
}

This paper is an elementary study of the normal and abnormal inter-atrial septum and an attempt to clarify the nomenclature and classification of the various kinds of septa on embryological grounds.

During fotal life, the left ventricle receives almost no blood from the lungs, and must therefore get it from the venæ cavæ via the common atrium, if it is to perform any work to help in its proper development. Herein lies the reason for the apparent complexity in the development of the interatrial septum because the septum must be so built that it will at all times in fœtal life allow blood to flow from right to left. Obviously a simple septum cannot do this, and the only solution is the natural one-the evolution of a one-way valvular partition, which allows the free flow of blood from right to left throughout fœtal life but can readily be closed by the rise of left atrial pressure that takes place at birth.

The simplest form of valve has two components, one fixed and the other moving. In the interatrial septum, the fixed component (or seating) is the thick septum secundum, and the moving component is the thin septum primum. In order that the valve shall open from right to left (and close in the reverse direction), the moving part must be on the left side of the fixed part, and so the septum primum forms to the left of the septum secundum.

Fig. 1 traces the evolution of the normal inter-atrial septum by means of cardboard models and sectional diagrams. Its understanding makes easier the study of the ostium primum and ostium secundum septal defects illustrated by models and photographs of actual specimens in Fig. 2 .

Apart from ostium primum and secundum defects, which are readily explained, there is another type of defect, more difficult to interpret, which may be associated with abnormal pulmonary venous drainage. An example is shown in Fig. 3, and the possible embryology is discussed. 


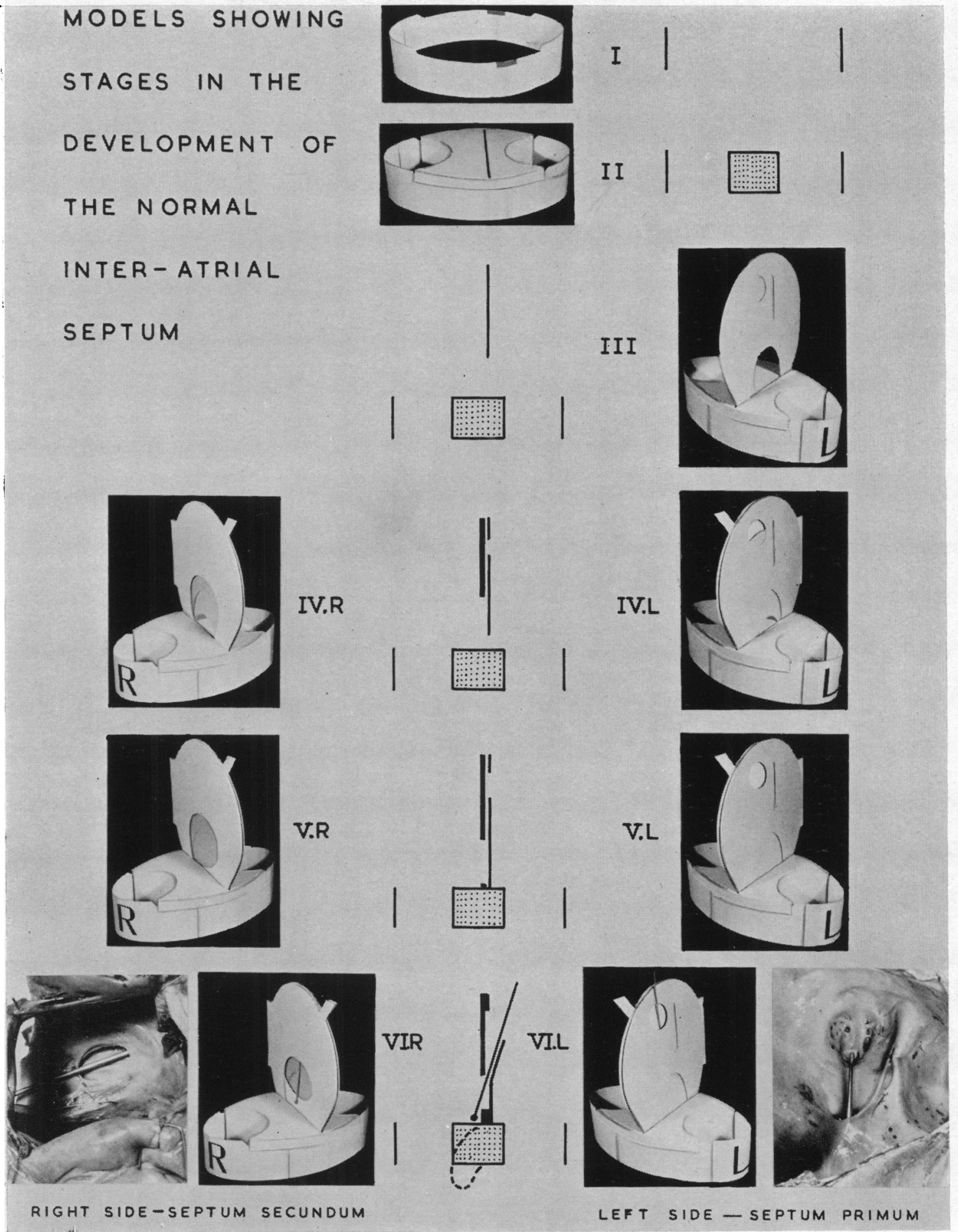

FIg. 1. 
Normal DeVelopment OF THE SePtum (Fig. 1)

I. The atrioventricular canal-the passage between the common atrium and ventricle.

II. The canal has been subdivided into mitral and tricuspid orifices by the union of endocardial cushions which grow towards each other from the front and back of the canal. The anteroposterior fissure indicates the site where the septa will meet the cushions.

III. The septum primum has appeared in the shape of a crescent-the aperture in its lower part is the ostium primum.

IV. L. and R. On the left side, the ostium primum is closing but at the same time a second aperture -the ostium secundum-is appearing by breakdown of the septum primum higher up. On the right side, the thicker septum secundum has appeared, at first being similar in appearance to the early septum primum. The broad and narrow projections indicate the positions of the inferior and superior venæ cavæ respectively.

V. L. and R. On the left side, the ostium primum is quite closed and the ostium secundum fully opened. On the right side the anterior limb of the septum secundum is growing across the base of the septum primum.

VI. L. and R. Completion of septum. On the left side, the septum primum is complete. On the right side, the anterior limb of the septum secundum has grown towards the inferior vena cava, so completing the foramen ovale, the thick margin of which is the annulus ovalis. The shallow fossa ovalis so formed is floored by septum primum.

The septum is now complete, and the septa partly stuck together, though blood can still flow into the foramen ovale and out from the ostium secundum as indicated by the knittingneedle. For comparison a typical example of this valvular foramen ovale is shown.

This state of affairs persists for several months after birth (though of course the valve is kept shut by the rise of pressure in the left atrium), and throughout life in about 15-20 per cent* of adults-the so-called patent foramen ovale. This is an ambiguous term since it implies that the foramen ovale may itself sometimes close up: this is very rare and it results in an imperforate interatrial septum and atresia of the left ventricle. In the remaining 80-85 per cent adults, the two septa become completely fused and the foramen ovale may be described as sealed. The sectional diagram indicates how the right portion of the fused endocardial cushions bends downwards to take part in the formation of the membranous part of the ventricular septum, the posterior part of which separates the right atrium from left ventricle.

* Author's own figure is 16 per cent of 100 adult hearts with normal inter-atrial septum. 
TYPES OF ATRIAL (AURICULAR) SEPTAL DEFECT
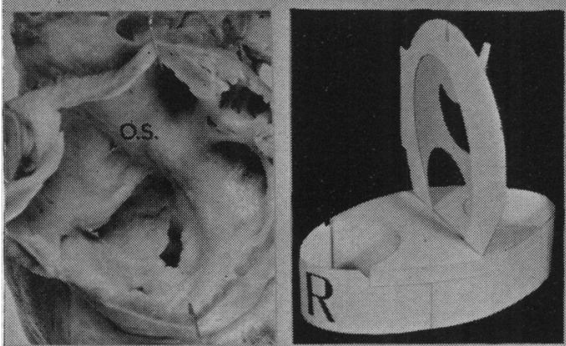

\section{A.}
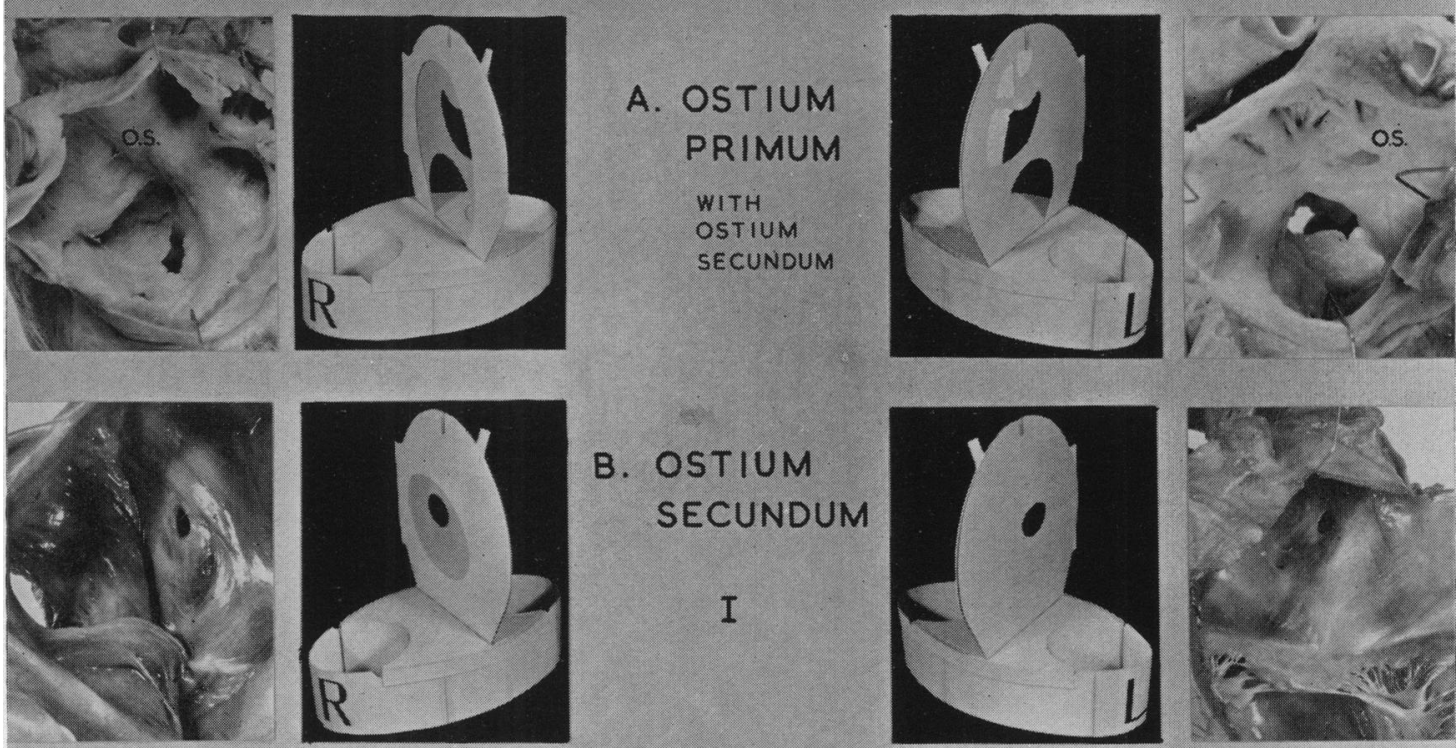

B. OSTIUM SECUNDUM
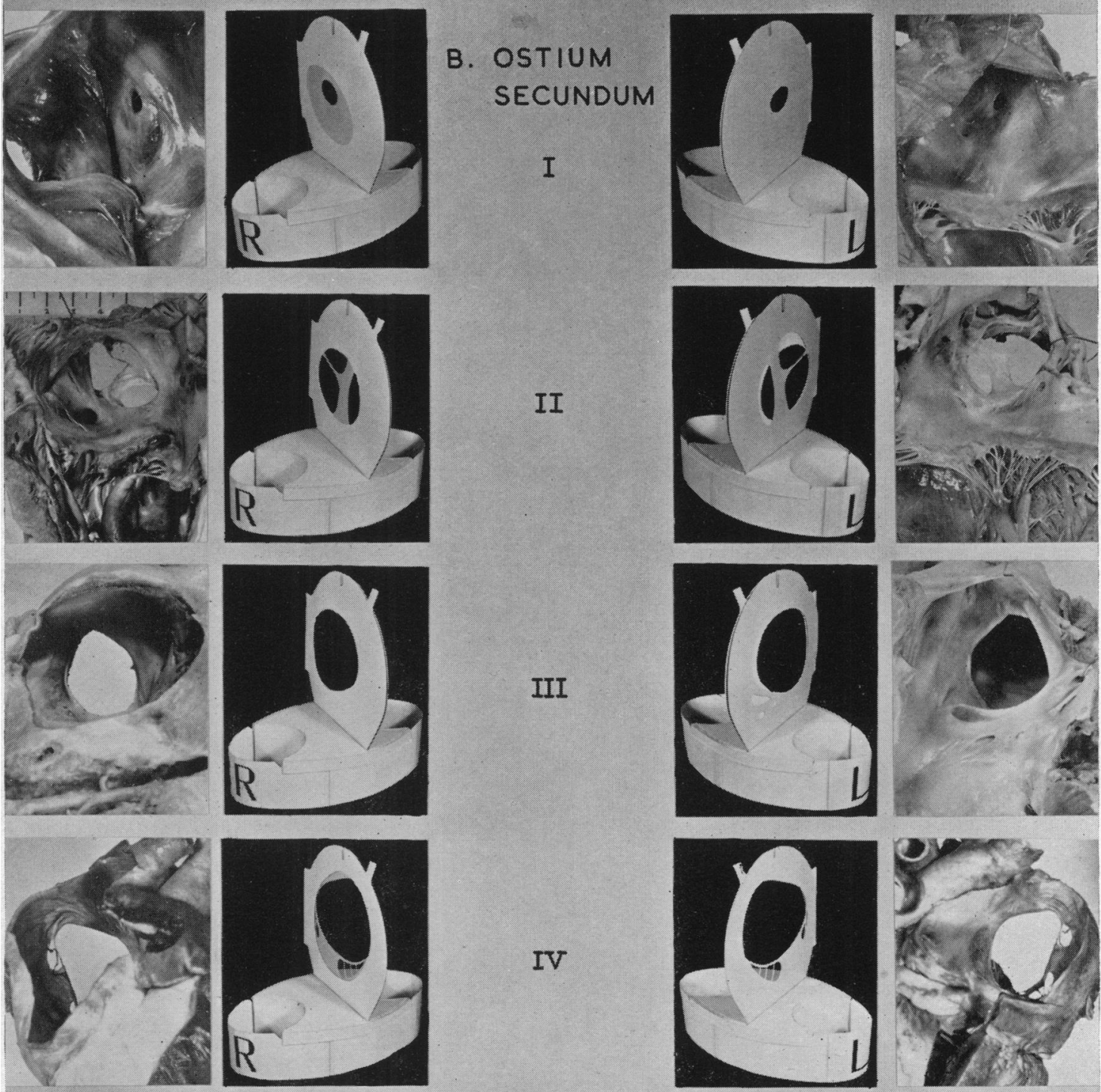

RIGHT SIDE - SEPTUM SECUNDUM

LEFT SIDE - SEPTUM PRIMUM

FIG. 2. 


\section{Types of Atrial Septal Defect (Fig. 2)}

An atrial septal defect is a permanent two-way communication between the right and left atria and it may arise in two main ways.

(1) When the septum primum and septum secundum do not completely overlap the ostium or ostia in each other (A and B and Fig. 2, A and B.)

(2) In association with abnormal pulmonary venous drainage (C and Fig. 3.)

\section{A. Ostium Primum Defect}

In the example illustrated, on the left side, the ostium primum has persisted, and above it, the septum primum has broken down into several holes (ostium secundum). On the right side, the septum secundum has also failed to develop across the ostium primum in the base of the septum primum, and has also left uncovered part of the ostium secundum, so this specimen shows both ostium primum and ostium secundum defects.

The tricuspid valve can be seen from the left atrium as well as from the right.

If the septum secundum had grown further down (or the ostium secundum appeared higher up), there would have been an ostium primum only, though the ostium secundum opening might have become valvular.

\section{B. Ostium Secundum Defect}

In this, the ostium secundum lies partially or completely in the same area as the foramen ovale. Four examples, in order of size, are illustrated.

I. From a case of congenital pulmonary valve stenosis. On the left side is a small ostium secundum which on the right side is seen to lie in the floor of a shallow fossa ovalis.

II. On the left side the ostium secundum is much larger but is still bridged by some ribbons of septum primum. On the right side, the foramen ovale is roughly the same size as the ostium secundum, and through it can be seen the strips of septum primum which bridge the ostium secundum.

III. On the left side the septum primum has broken down even further, resulting in one large ostium secundum with one or two smaller ostia nearby. On the right side the foramen ovale almost exactly corresponds with the ostium secundum.

IV. On the left side there has been almost complete breakdown of the septum primum, though around the periphery are some fenestrated remnants. On the right side is a huge foramen ovale, even larger than the main ostium secundum. This example represents virtually a single atrium. 


\section{Defect Associated with Abnormal Development of the Pulmonary Venous Drainage}

In the normal heart, the pulmonary veins open into that part of the left atrium known as the vestibule. Keith (1948) states that it is highly probable that in the human the vestibule of the left atrium is a leftward extension of the sinus venosus, as in amphibians. This extension towards the left side of the common atrium normally becomes cut off from the main sinus venosus in the human by the inter-atrial septum so that the pulmonary veins come to open into (the vestibule of) the left atrium.

In fishes, the " pulmonary vein" (from the swim bladder) enters the sinus venosus. In man, if the pulmonary veins enter the sinus venosus, they will come to open into the right atrium since the sinus venosus becomes incorporated into the right atrium, being roughly that part of the posterior wall between the venæ cavæ and the coronary sinus. It is worth noting in passing that the pulmonary veins have also been recorded in man as entering the right and left ducts of Cuvier or their terminations, the right and left horns of the sinus venosus. The left duct and horn form the left superior vena cava (which usually survives only as the tiny vein of Marshall) and the coronary sinus. The right duct and horn form the part of the right superior vena cava below the azygos vein.

Now if some of the pulmonary veins enter the main sinus venosus, and the others enter the leftward extension of the main sinus which forms the vestibule of the left atrium, and if this extension maintains its communication with the main sinus, then some pulmonary veins will come to open into the right atrium, and the remainder into the vestibule of the left atrium (as normally) and there will be an interatrial septal defect where the main sinus and its extension communicate.

In the example shown in Fig. 3, on the left side can be seen an ostium secundum defect (O.S.),

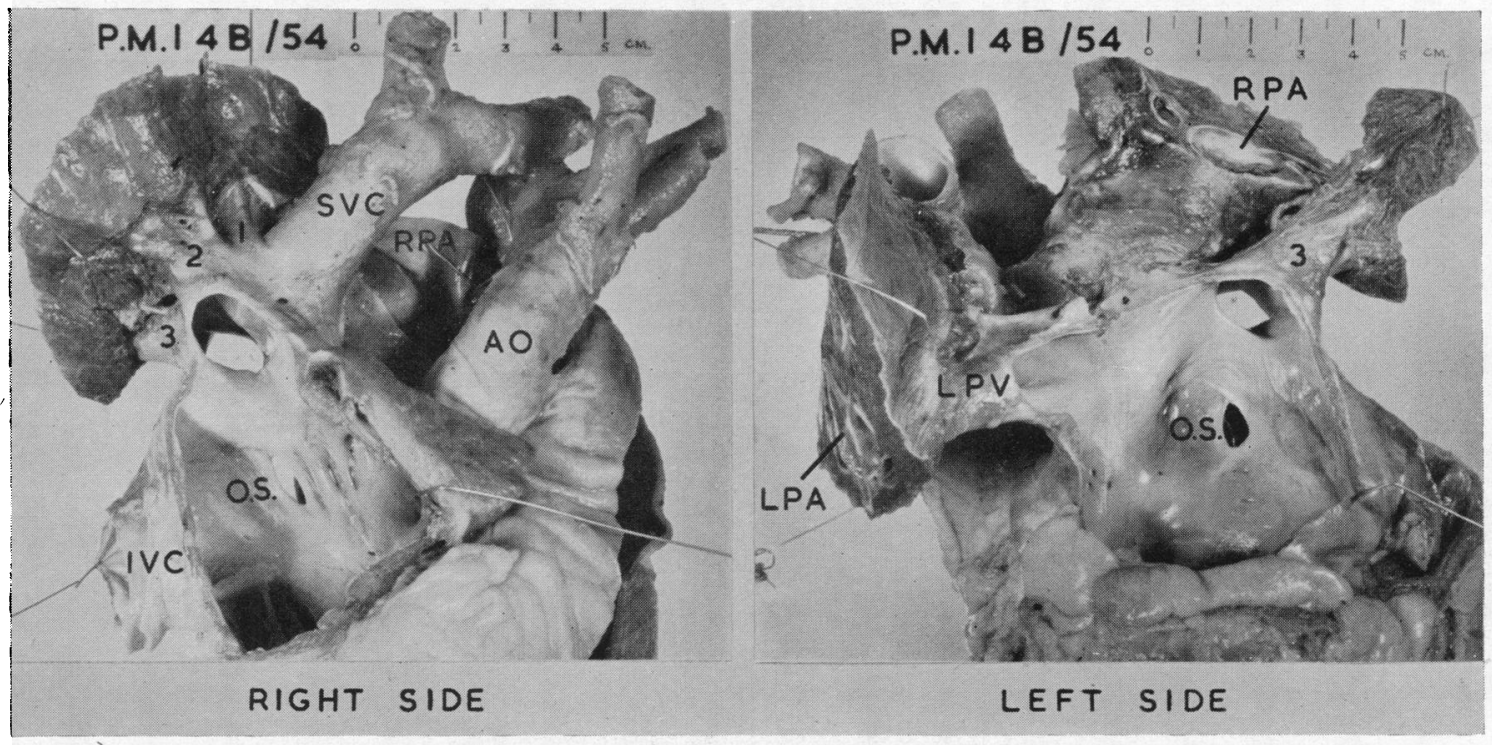

FIG. 3.

but above it is a much larger septal defect, to the left atrial side of which the lower right pulmonary vein (3) opens. The left pulmonary veins (LPV) enter normally. Note the complete occlusion of both main pulmonary arteries (LPA and RPA) by thrombus-a not uncommon complication of atrial septal defect.

On the right side is the small ostium secundum defect (O.S.) in the antero-superior part of the fossa ovalis. Above this is the larger septal defect to the right atrial side of which opens the superior vena cava (SVC) and the upper two main right pulmonary veins $(1,2)$. The lower right pulmonary 
vein (3) opens mainly into the left atrium. The right main pulmonary artery (RPA) is shown opened and filled with thrombus. IVC is the inferior vena cava and AO the aorta.

The large septal defect may therefore be a persistence of the communication between the main sinus venosus (which incorporates into the right atrium into which the upper right pulmonary veins have come to open) and its leftward extension which forms the vestibule of the left atrium (into which enter all the left pulmonary veins and the lower right pulmonary vein).

\section{Classification}

On the basis of the above account the following classification of the inter-atrial septum is suggested.

NoRMAL SEPTUM-Septa overlapping each other's ostium completely.

$$
\text { Foramen ovale } \quad \ldots \quad \ldots \quad \ldots \quad \text { - } \quad \text { - valvular (unsealed) }
$$

Abnormal SePtum-Atrial (Auricular) Septal Defect

$A$ and $B$. Septa not overlapping each other's ostium or ostia completely.

$$
\begin{aligned}
& \text { A. Ostium primum .. . }\left[\begin{array}{r}
\text { with ostium secundum } \\
\text { (example illustrated) } \\
\text { with valvular " foramen }
\end{array}\right. \\
& \text { ovale" (as described by } \\
& \text { Bedford, Papp, and } \\
& \text { Parkinson, 1941). }
\end{aligned}
$$

B. Ostium secundum $\quad$.. (4 examples illustrated).

C. Associated with abnormal pulmonary venous drainage.

This defect may be accompanied by another defect elsewhere in the septum such as an ostium secundum defect, as in the example shown (Fig. 3).

\section{SUMMARY}

An illustrated account is given of the development of the normal inter-atrial septum, and of various forms of atrial septal defect resulting either from failure of septum primum and septum secundum to cover each other's ostium or ostia, or from the development of an abnormal pulmonary venous drainage. Finally a simple classification is suggested based on modern embryological nomenclature.

I should like to express my thanks to Mrs. O. Connolly for her help with the photography.

Part of this paper was demonstrated during 1954 to the British Cardiac Society in Cambridge, the Pathological Society of Great Britain in Edinburgh, and to the Society of Thoracic Surgeons in London.

\section{REFERENCES}

Bedford, D. E., Papp, C., and Parkinson, J. (1941). Brit. Heart J., 3, 37.

Gould, S. E. (1953). Pathology of the Heart. Thomas, Springfield, U.S.A.

Hamilton, W. S., Boyd, J. D., and Mossman, H. W. (1952). Human Embryology. Heffer and Sons, Cambridge. Hudson, R. (1954). Brit. Heart J., 16, 472.

Keith, A. (1948). Human Embryology and Morphology. Arnold, London. 